\title{
Experimental Investigation of Hot Spot Factor for Assessing Hot Spot Temperature in Transformers
}

DOI:

10.1109/CMD.2016.7757981

\section{Document Version}

Accepted author manuscript

Link to publication record in Manchester Research Explorer

\section{Citation for published version (APA):}

Daghrah, M., Wang, Z., Liu, Q., Walker, D., Krause, C., \& Wilson , G. (2016). Experimental Investigation of Hot Spot Factor for Assessing Hot Spot Temperature in Transformers. In The international conference on Condition Monitoring and Diagnosis 2016 (CMD 2016) (Proceedings of the IEEE). IEEE.

https://doi.org/10.1109/CMD.2016.7757981

Published in:

The international conference on Condition Monitoring and Diagnosis 2016 (CMD 2016)

\section{Citing this paper}

Please note that where the full-text provided on Manchester Research Explorer is the Author Accepted Manuscript or Proof version this may differ from the final Published version. If citing, it is advised that you check and use the publisher's definitive version.

\section{General rights}

Copyright and moral rights for the publications made accessible in the Research Explorer are retained by the authors and/or other copyright owners and it is a condition of accessing publications that users recognise and abide by the legal requirements associated with these rights.

\section{Takedown policy}

If you believe that this document breaches copyright please refer to the University of Manchester's Takedown Procedures [http://man.ac.uk/04Y6Bo] or contact uml.scholarlycommunications@manchester.ac.uk providing relevant details, so we can investigate your claim.

\section{OPEN ACCESS}




\title{
Experimental Investigation of Hot Spot Factor for Assessing Hot Spot Temperature in Transformers
}

 \\ ${ }^{1}$ The University of Manchester, Manchester, M13 9PL, UK \\ ${ }^{2}$ Scottish Power, Blantyre, G72 0HT, UK \\ ${ }^{3}$ Weidmann Electrical Technology AG, Rapperswil, CH 8640, Switzerland \\ ${ }^{4}$ National Grid, Warwick, CV34 6DA, UK \\ * zhongdong.wang@manchester.ac.uk
}

\begin{abstract}
Ageing of paper insulation within oil immersed power transformers is the determining factor for the transformer expected life. A thermal diagram as shown in the IEC 600762:2011 standard specified a hot spot factor method to estimate the hot spot temperature based on heat run test data. The hot spot factor is split into a $Q$ factor, which depends on loss distribution within winding, and an $\mathrm{S}$ factor, which depends on oil flow distribution within winding cooling ducts. In this paper, an experiment is conducted on a disc type winding model to study the hot spot factor under fixed winding geometries subjected to wide range of inlet flow rates and uniform or non-uniform power loss injections. The hot spot factor is calculated from measured temperatures within the winding model using thermocouples. The hot spot factor was decoupled by applying first uniform losses to calculate the $S$ factor and then nonuniform losses to calculate the $Q$ factor. It was observed that the hot spot factor is lower for more uniform temperature profiles. It was observed that the $S$ and $Q$ factors are interdependent and cannot be decoupled.
\end{abstract}

Keywords-Hot Spot; Thermal modelling; Experiment; Transformer

\section{INTRODUCTION}

In-service ageing of a power transformer is mainly determined by its Hot Spot Temperature (HST), defined as the hottest temperature within the transformer winding. The HST is affected by transformer winding geometries, total winding flow rate and loss distribution within the winding. It is widely accepted that ageing rate of paper insulation doubles each $6 \mathrm{~K}$ rise above the rated HST [1-2]. Prediction of the HST requires detailed knowledge of transformer winding geometries, flow distribution within the winding cooling ducts and loss distribution within the winding. An empirical method is given in the IEC 60076-2:2011 to estimate HST using heat run test data and a predefined Hot Spot Factor $(H)$.

During a heat run test, the ambient temperature $\theta_{a}$, the bottom oil temperature rise $\Delta \theta_{b}$, the top oil temperature rise $\Delta \theta_{o}$ and the mean winding temperature rise $\Delta \theta_{w}$ are recorded. Measured temperature rises during a heat run test are presented on a thermal diagram as shown in Fig. 1 in which oil and winding temperature rises are assumed linear along winding height [2]. The gradient $g$ is the temperature difference between the mean oil temperature rise $\Delta \theta_{\text {om }}$ and $\Delta \theta_{w}$. The HST rise $\Delta \theta_{h}$ is estimated using equation (1) where $H$ is the Hot Spot Factor.
Presenting the $H$ with an analytical formula was considered by [3] and it was concluded that it is not reasonable to recommend any analytical formula for it. From a collection of heat run tests which included measurements of the HST using fibre optics, it was found that among the transformers studied the $H$ ranged from 0.51 to 2.06 [3]. It was observed in [3] that the $H$ does not depend on cooling mode or transformer power level. The $H$ was calculated and presented in [4] from a set of thermal tests on Oil Natural Air Natural (ONAN), Oil Natural Air Forced (ONAF) and Oil Directed Air Forced (ODAF) power transformers. It was found that for studied transformer types, the average value of the calculated $H$ is 1.3 . The effective $H$ was deduced based on paper samples obtained from 35 scrapped transformers [5] and it was found that on average the effective $H$ value is 2.95 , a much higher value than the assumed 1.3. It was specified in the IEC standard [2] that the $H$ can be presented as multiplication of two separate factors $Q$ and $S$. The $Q$ factor represents the loss distribution whereas the $S$ factor represents the nonuniformity of flow distribution within cooling ducts. A detailed thermal-hydraulic network model was used by [6] to study a 100-MVA power transformer and the results were used to calculate the $H$ and both $Q$ and $S$ factors. It was concluded that the $S$ and $Q$ factors are not decoupled. It was also observed that the $S$ factor depends on loading level and loss distribution as this affect oil viscosity which influences flow distribution. It was concluded that the concept of the $S$ and $Q$ factors as defined in the IEC 600762:2011 might not be particularly meaningful [6].

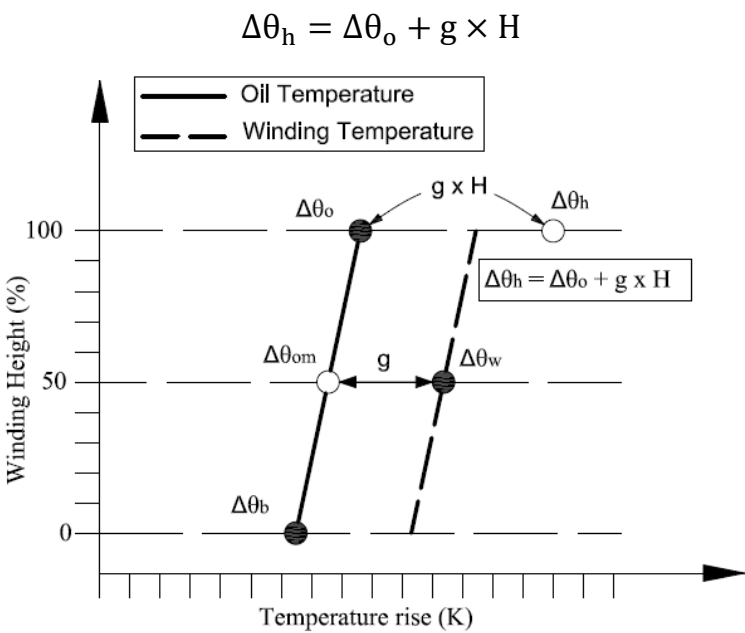

Fig. 1. Thermal diagram according to IEC 60076-2:2011 [2] 
In this paper, an experiment is conducted on a disc type winding model to study the $H, S$ and $Q$ factors subjected to uniform and nonuniform losses under OD cooling mode. The experimental setup is presented in Section II. The effect of inlet flow rate on the $H$ is captured. Thermal tests were conducted and all required data to calculate the $H$ were measured and presented in Section III. Finally, Section IV provides a discussion of the results.

\section{EXPERIMENTAL SETUP}

The experimental setup consists of a disc type winding model, a radiator, a pump and a flow meter as shown in Fig. 2. The experimental setup was described in more details in [7]. An external heating unit is added outside of the winding model to control oil inlet temperature. Brief descriptions of the system components are given as follows:

\section{A. Disc type winding model}

The winding model consists of three passes and each pass hosts 10 disc segments, henceforth plates. Each plate was heated using two cartridge heaters located within each plate as shown in Fig. 3. Plates were made of aluminum blocks with $104 \mathrm{~mm} \times 100 \mathrm{~mm} \times 10 \mathrm{~mm}$ dimensions. Paper was not wrapped over plates due to the induced difficulty in assembling. This would cause lower $\Delta \theta_{w}$ than if plates were wrapped and hence affect the calculated $H$, which will be discussed in section IV. Baffles were made from acrylic sheets with the same thickness as the plates. Two thermocouples were fitted in each plate $10 \mathrm{~mm}$ from each end as shown in Fig. 3. Two thermocouples were used to measure winding model inlet temperature and 1 thermocouple was used to measure winding model outlet temperature. The height of each Horizontal Duct (HD) is $4 \mathrm{~mm}$. Both the Vertical Ducts (VD) have the same width of $12 \mathrm{~mm}$.

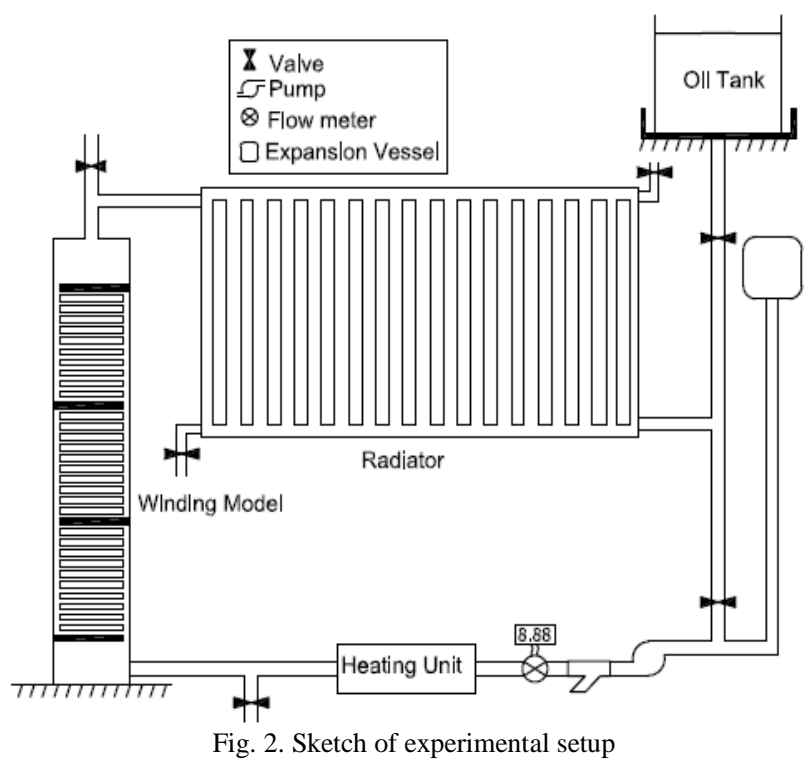

\section{B. Instrumentations used}

A multi-channel temperature acquisition system was implemented to provide 64 thermocouple channels. The system was calibrated in a water bath and an accuracy of $+\mathrm{l}-1$
${ }^{\circ} \mathrm{C}$ was achieved. Inlet flow rate was measured using a positive displacement flow meter with an accuracy of $+1-0.5 \%$ of reading. Multiple variable autotransformers, variac, were used to control power injection to simulate uniform or nonuniform loss distributions. The current and voltage were measured to record the power injection per plate.

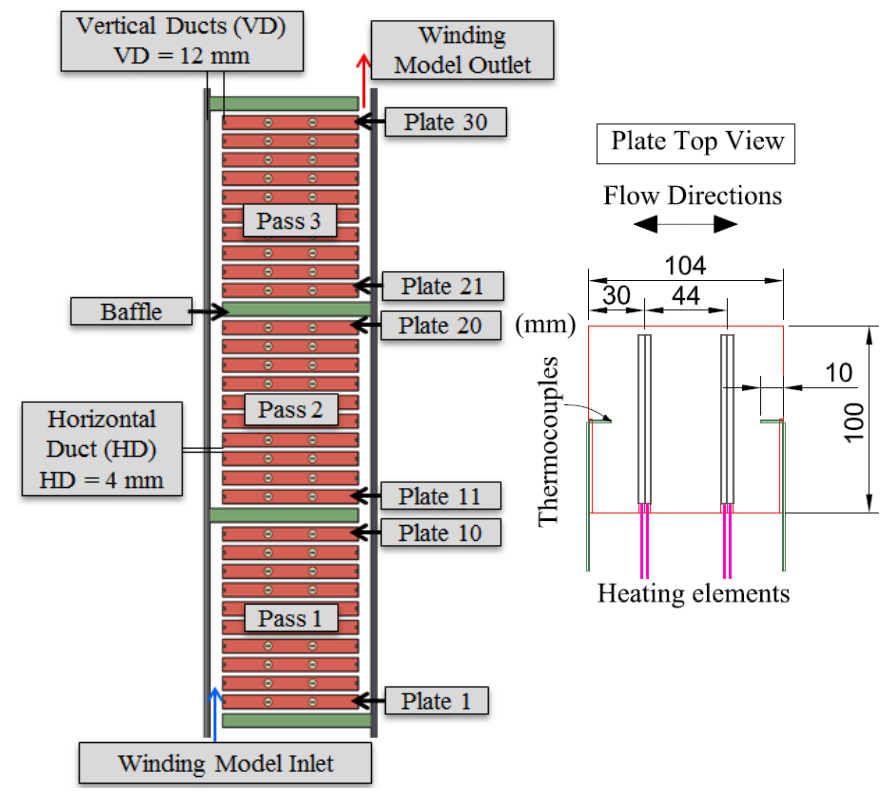

Fig. 3. Winding model and plate geometries

\section{TEST RESULTS}

In order to decouple the $H$ into the $S$ and the $Q$ factors, two tests are conducted under uniform and nonuniform loss distributions as shown in Table I. Assuming that a plate models a power transformer copper disc segment with a current density of $4 \mathrm{~A} / \mathrm{mm}^{2}$ [1]; $50 \mathrm{~W}$ per plate, or equivalently near 2100 $\mathrm{W} / \mathrm{m}^{2}$ power flux density, was assumed which would accommodate for DC copper losses, eddy current losses and stray losses within the winding lower discs. Extra power was injected in top top 5 plates to simulate eddy current losses.

\section{A. Hot spot factor under uniform losses}

Inlet flow rate (FR) was changed from 3 litres/minute (lpm) to $18 \mathrm{lpm}$, equivalent average winding inlet velocities are shown on Fig. 4. The total power injection was maintained constant at $50 \mathrm{~W}$ per plate. Fig. 4 shows the average winding model temperature profiles for each plate under different flow rates. Table II shows the temperature rises and the calculated $H$. The $H$ is calculated using equation (1). Since losses are uniform, the $Q$ factor was assumed $1.0[2,6]$. The $S$ factor, by definition, was calculated using $H=S \times Q$. It can be observed that the temperature profile is more distorted at higher flow rates due to nonuniform oil flow distribution within horizontal cooling ducts. From Table II, the calculated $H$ is higher for higher flow rates even though the HST is lower.

\section{TABLE I POWER LOSS DISTRIBUTION FOR UNIFORM AND} NONUNIFORM CASES

\begin{tabular}{|c|c|c|c|c|c|c|}
\hline Plate Number & P1-P25 & P26 & P27 & P28 & P29 & P30 \\
\hline Uniform Power $(\mathrm{W})$ & 50 & 50 & 50 & 50 & 50 & 50 \\
\hline Non-uniform Power $(\mathrm{W})$ & 50 & 60 & 76 & 95 & 111 & 132 \\
\hline
\end{tabular}


TABLE II TEMPERATURE RISES TO CALCULATE H UNDER UNIFORM LOSSES

\begin{tabular}{|c|c|c|c|c|c|c|c|c|c|c|}
\hline \multirow[b]{2}{*}{$\begin{array}{c}\text { FR } \\
\text { lpm }\end{array}$} & \multirow[b]{2}{*}{$\begin{array}{c}\boldsymbol{\theta}_{\mathrm{a}} \\
\left({ }^{\circ} \mathrm{C}\right)\end{array}$} & \multicolumn{6}{|c|}{ Temperature Rises } & \multicolumn{3}{|c|}{ H calculation } \\
\hline & & $\begin{array}{l}\Delta \boldsymbol{\theta}_{\mathrm{o}} \\
\left({ }^{\circ} \mathrm{C}\right)\end{array}$ & $\begin{array}{l}\Delta \boldsymbol{\theta}_{\mathrm{b}} \\
\left({ }^{\circ} \mathrm{C}\right)\end{array}$ & $\begin{array}{l}\Delta \boldsymbol{\theta}_{\mathrm{om}} \\
\left({ }^{\circ} \mathrm{C}\right)\end{array}$ & $\begin{array}{c}\Delta \boldsymbol{\theta}_{\mathrm{w}} \\
\left({ }^{\circ} \mathrm{C}\right)\end{array}$ & $\begin{array}{l}\Delta \boldsymbol{\theta}_{\mathrm{h}} \\
\left({ }^{\circ} \mathrm{C}\right)\end{array}$ & $\underset{\left({ }^{\circ} \mathrm{C}\right)}{\mathbf{g}}$ & HSF & $\mathbf{S}$ & $\mathbf{Q}$ \\
\hline 3 & 20 & 60 & 49 & 55 & 69 & 77 & 15 & 1.1 & 1.1 & 1.0 \\
\hline 6 & 20 & 58 & 54 & 56 & 70 & 75 & 14 & 1.2 & 1.2 & 1.0 \\
\hline 12 & 20 & 59 & 55 & 57 & 68 & 76 & 11 & 1.6 & 1.6 & 1.0 \\
\hline 18 & 19 & 56 & 53 & 55 & 64 & 72 & 10 & 1.6 & 1.6 & 1.0 \\
\hline
\end{tabular}

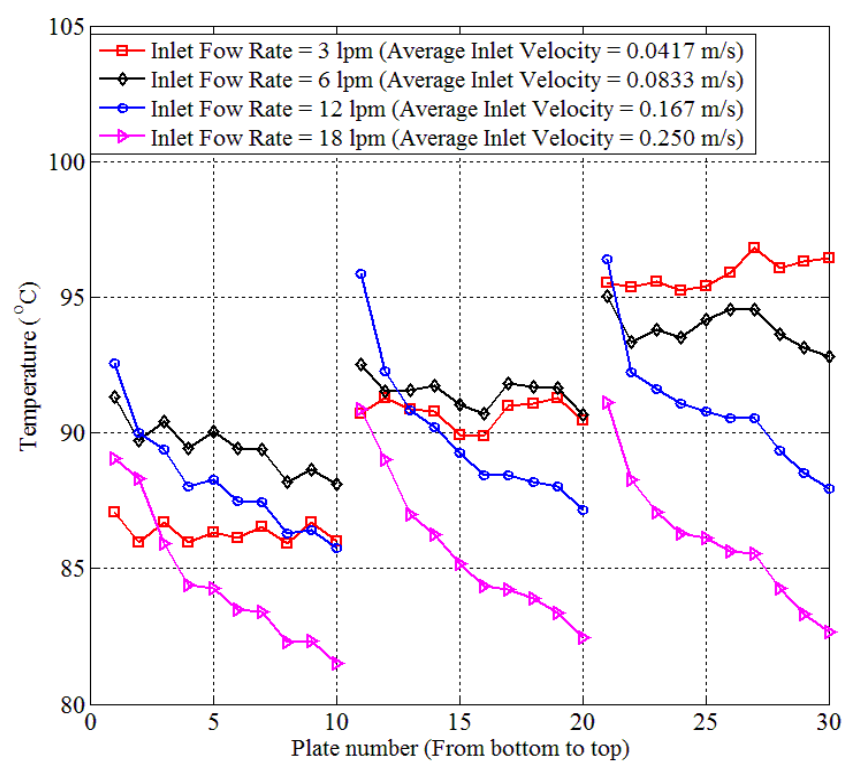

Fig. 4 Average winding model temperature profiles under uniform losses

Nonuniform losses were applied and fixed to a total of $1724 \mathrm{~W}$, as shown in Table I and Fig. 5, under same range of inlet flow rates. Winding model temperature profiles are shown in Fig. 6 and the measured temperature rises are summarized in Table III. The $S$ factor was assumed equal to that found in the previous uniform loss case, shown in Table II, since the winding model geometries and the tested range of inlet flow rates are the same.

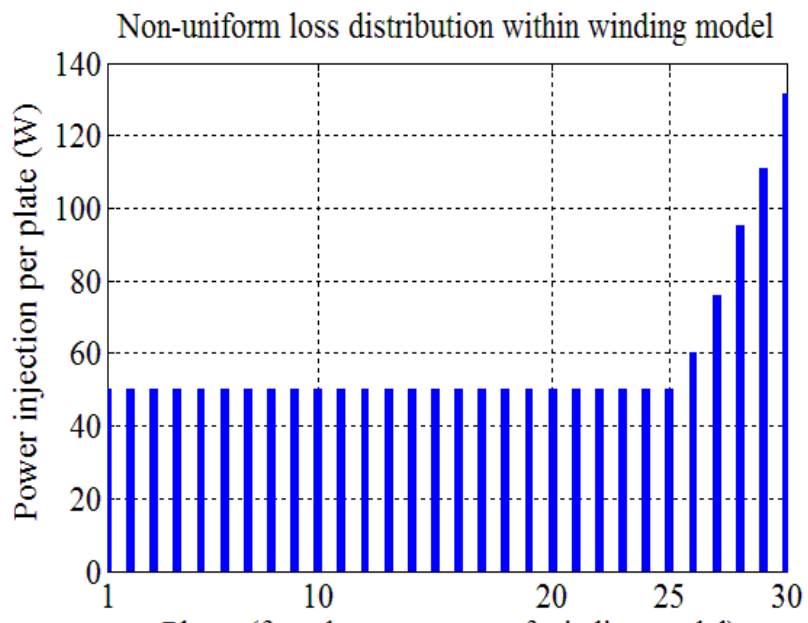

Plates (from bottom to top of winding model)

Fig. 5 Loss distribution (numerical values shown in Table I)
In both uniform and nonuniform cases, the bottom oil temperatures are almost similar, within $4^{\circ} \mathrm{C}$ differences, so oil viscosities at winding inlet can be considered similar for each flow rate between the two cases. It can be observed that the temperature profile is more distorted at lower flow rates. On the contrary of the uniform loss case, the $H$ is lower at higher flow rates since the temperature profile is less distorted and so the HST rise is closer to $\Delta \theta_{w}$. Despite the fact that nonuniform losses are fixed for all flow rates, the $Q$ factor decreased with the increase of inlet flow rate.

\section{TABLE III TEMPERATURE RISES TO CALCULATE H UNDER NONUNIFORM LOSSES}

\begin{tabular}{|c|c|c|c|c|c|c|c|c|c|c|}
\hline \multirow[b]{2}{*}{$\begin{array}{r}\text { FR } \\
\text { lpm }\end{array}$} & \multirow[b]{2}{*}{$\begin{array}{c}\boldsymbol{\theta}_{\mathrm{a}} \\
\left({ }^{\circ} \mathrm{C}\right)\end{array}$} & \multicolumn{6}{|c|}{ Temperature Rises } & \multicolumn{3}{|c|}{ H calculation } \\
\hline & & $\begin{array}{l}\Delta \boldsymbol{\theta}_{\mathrm{o}} \\
\left({ }^{\circ} \mathrm{C}\right)\end{array}$ & $\begin{array}{l}\Delta \boldsymbol{\theta}_{\mathrm{b}} \\
\left({ }^{\circ} \mathrm{C}\right)\end{array}$ & $\begin{array}{l}\Delta \boldsymbol{\theta}_{\mathrm{om}} \\
\left({ }^{\circ} \mathrm{C}\right)\end{array}$ & $\begin{array}{l}\Delta \boldsymbol{\theta}_{\mathrm{w}} \\
\left({ }^{\circ} \mathrm{C}\right)\end{array}$ & $\begin{array}{l}\Delta \boldsymbol{\theta}_{\mathrm{h}} \\
\left({ }^{\circ} \mathrm{C}\right)\end{array}$ & $\begin{array}{c}\mathbf{g} \\
\left({ }^{\circ} \mathrm{C}\right)\end{array}$ & HSF & $\mathbf{S}$ & $\mathbf{Q}$ \\
\hline 3 & 21 & 63 & 49 & 56 & 72 & 101 & 15 & 2.4 & 1.1 & 2.2 \\
\hline 6 & 21 & 57 & 51 & 54 & 68 & 88 & 15 & 2.2 & 1.2 & 1.8 \\
\hline 12 & 21 & 55 & 51 & 53 & 65 & 79 & 12 & 2.1 & 1.5 & 1.4 \\
\hline 18 & 21 & 54 & 51 & 53 & 62 & 73 & 10 & 1.9 & 1.6 & 1.2 \\
\hline
\end{tabular}



Fig. 6. Average winding model temperature profiles under nonuniform losses

\section{DisCUSSION}

The HST is affected by three contributors which are the oil flow rates within horizontal cooling ducts, the oil flow distribution within each pass and the axial and radial loss distributions within the winding. The $H$ is used to empirically compensate for the lack of knowledge of the three contributors by using accumulated experience and the data from heat run tests. The $H$ is split into the $Q$ and $S$ factors. The $S$ factor is affected by uniformity of flow distribution within the winding. The uniformity of oil distribution depends greatly on winding geometries and winding inlet oil flow rates. In the uniform loss tests, it was observed that higher inlet flow rates created more distorted temperature profiles. The $Q$ factor was fixed and set to 1.0 since all the plates had the same power injection. The $H$ was calculated from tests data shown in Table II and 
the $S$ factor was then derived from the $H$ and the known $Q$ factor. It was observed that higher flow rates created higher $H$ despite the fact that the HST is lower as can be seen by comparing temperature rises for $\mathrm{FR}=3 \mathrm{lpm}$ and $\mathrm{FR}=18 \mathrm{lpm}$. This indicates that higher $H$ does not necessarily correspond to higher HST as can be seen in the uniform loss case.

For the nonuniform loss case, similar flow rates and inlet oil temperatures to those of the uniform loss case were reached. This justifies the assumption that the $S$ factor from the uniform loss case can be used in the $H$ calculation in the nonuniform loss case. The nonuniform losses were fixed for all inlet flow rates and it was observed that higher flow rates lead to lower $H$ and lower HST. Even though the loss distribution is fixed, it was observed that the $Q$ factor is lower for higher inlet flow rates; indicating that the $S$ and $Q$ factors are interdependent.

Inlet flow rate affects the uniformity of the developed temperature profile. Under uniform loss distribution, it can be observed that higher flow rates create more distorted temperature profiles and lower the HST but the $H$ was higher, comparing FR $=3 \mathrm{lpm}$ and FR $=18 \mathrm{lpm}$ in Table II. On the contrary, for nonuniform loss distribution higher flow rates created more uniform temperature profiles and lower HST as well as lower $H$. From this observation, it can be concluded that the $H$ is affected by the uniformity of winding temperature profile which is shaped by both the oil flow distribution and the loss distribution.

Disc segments were modelled in this work using rectangular aluminium plates without paper. This simplification affects both the average winding temperature and the HST. For wrapped composite discs, both the HST and the average winding temperature would be higher; this would make the calculated $H$ slightly lower, since $g$ would be higher.

\section{CONCLUSION}

In this paper, an experimental setup was used to conduct artificial heat run tests on a disc type winding model. All temperature rises required to calculate the Hot Spot Factor $(H)$ were recorded using thermocouples. The inlet flow rate was changed from $3 \mathrm{lpm}$ to $18 \mathrm{lpm}$ and both uniform and nonuniform power injection were applied in order to decouple the $H$ into its two defined $S$ and $Q$ components by the IEC 60076-23:2011 standard. It was demonstrated that the $S$ and $Q$ factors are interdependent and cannot be decoupled. It was observed that the $H$ is affected by inlet flow rate. Under uniform losses, the $H$ factor increased with increasing flow rate though the HST is lower at higher flow rates. On the other hand, it was observed that the $\mathrm{H}$ factor decreased with increasing flow rates for nonuniform losses and so was the HST.

\section{ACKNOWLEDGMENT}

The authors would like to express their gratitude to M\&I Materials, National Grid, Scottish Power, Shell, TJ/H2b Analytical Services, UK Power Networks and Weidmann Electrical Technology for their financial and technical contributions to the Transformer Research Consortium at The University of Manchester.

\section{REFERENCES}

[1] M. Heathcote, "J\&P transformer book", 13th ed., Oxford, pp.158-167, 2007

[2] IEC 60076-2:2011, "Power transformers-Part 2: Temperature rise for liquid-immersed transformers", BSI, 2011

[3] CIGRE Working Group 12.09, "Thermal Aspects of Transformers", Tech. Brochure No. 96, 1995

[4] CIGRE Working Group A2.24, "Thermal Performance of Transformers", Tech. Brochure No. 393, 2009

[5] D. Feng, Z. D. Wang and P. Jarman, "Evaluation of Power Transformers' Effective Hot-Spot Factors by Thermal Modelling of Scrapped Units", IEEE Tran. Power Del., vol. 29, no. 5, pp 2077-2085, Oct. 2014

[6] Z. Radakovic, U. Radoman and P. Kostic, "Decomposition of the HotSpot Factor", IEEE Tran. Power Del., vol. 30, no. 1, pp 403 - 441, Feb. 2015

[7] M. Daghrah, Z. D. Wang, Q. Liu, D. Walker, P. W. R. Smith and P. Mavrommatis, "Design of Experimental Setup to Study Factors Affecting Hot Spot Temperature in Disc Type Winding Transformers", The IET Int. Conf. on Resilience of Transmission and Distribution Networks, Birmingham, 2015

[8] P. Picher, F. Torriano, M. Chaaban, S. Gravel, C. Rajotte and B. Cirard, "Optimization of transformer overload using advanced thermal modelling", in Cigre Conference, Paris, France, pp. A2-305, 2010 